\title{
EFEK GAYA VERTIKAL PADA TANAH DENGAN INDEKS PLASTISITAS TINGGI TERHADAP WILAYAH SEKITAR PROYEK DI JAKARTA UTARA
}

\author{
Staventram Inri ${ }^{1}$ dan Alfred Jonathan Susilo ${ }^{2}$ \\ ${ }^{1}$ Program Studi Sarjana Teknik Sipil, Universitas Tarumanagara, J1. Letjen S. Parman No.1 Jakarta \\ staventram.inri@gmail.com \\ ${ }^{2}$ Program Studi Sarjana Teknik Sipil, Universitas Tarumanagara, Jl. Letjen S. Parman No.1 Jakarta \\ alfred@ft.untar.ac.id
}

Masuk: 20-01-2020, revisi: 24-04-2020, diterima untuk diterbitkan: 13-05-020

\begin{abstract}
Soil improvement is common in construction work to increase the bearing capacity of the soil so the soil can carry the burden of construction which will stand on that soil. The method often used is soil compaction to increase bearing capacity. Soil compaction results in a lateral movement of soil particles and causes an increase in soil pore water pressure. Soil compaction here uses drum roller and dynamic compaction. This gives an effect at a certain distance and has the potential to damage the surrounding buildings. Therefore, the engineer needs to predict a safe distance from the effects of the compaction process. This research conducted with theoretical predictions about the amount of lateral movement due to compaction with certain formulas. The same thing will happen when the driven pile is piling, it will cause around the pile lift up (pile heaving). The results of this theoretical prediction will be compared then compare with the results of measurements of lateral movements performed using general shear failure from Terzaghi method and stress distribution Boussinesq method. Both of the results will be compared as conclusions.
\end{abstract}

Keywords: high plasticity soil; compaction; driven; lateral impulse; pile heaving.

\begin{abstract}
ABSTRAK
Perbaikan tanah sudah umum dilakukan dalam pekerjaan konstruksi dengan tujuan untuk meningkatkan daya dukung tanah agar dapat memikul beban konstruksi yang akan berdiri di atasnya. Metode yang sering digunakan yaitu pemadatan tanah untuk meningkatkan daya dukungnya. Pemadatan tanah mengakibatkan desakan butiran tanah ke arah lateral serta menimbulkan kenaikan tekanan air pori tanah. Pemadatan disini menggunakan tandem roller dan dynamic compaction. Hal ini memberikan pengaruh hingga jarak tertentu dan berpotensi merusak bangunan di sekitar. Oleh karena itu, perlu diprediksi jarak yang aman dari pengaruh proses pemadatan. Penelitian ini dilakukan dengan prediksi teoritis besarnya pergerakan tanah ke arah lateral akibat pemadatan dengan formula tertentu. Hal yang serupa juga sama ketika tiang pancang ditumbuk, akan menyebabkan tiang di sebelahnya terangkat (pile heaving). Hasil prediksi secara teori ini kemudian dibandingkan dengan hasil pengukuran kegagalan geser berdasarkan metode Terzaghi dan distribusi tegangan Boussinesq. Hasil keduanya akan dibandingkan sebagai kesimpulan.
\end{abstract}

Kata kunci: tanah plastisitas tinggi; pemadatan; pemancangan; pergerakan tanah lateral; terangkatnya tiang.

\section{PENDAHULUAN}

\section{Latar belakang}

Terdapat beberapa kriteria penting yang harus diketahui dari tanah yang hendak didirikan suatu bangunan terutama dari segi jenis, sifat dan kekuatan tanah. Kekuatan tanah banyak bergantung pada kandungan air dalam tanah, jenis tanah dan keadaan asal dari tanah. Salah satu faktor yang dapat meningkatkan daya dukung tanah adalah pemadatan tanah. Pemadatan tanah merupakan suatu proses menaikkan kerapatan tanah dengan memperkecil jarak antar partikel melalui pengeluaran udara dari pori-pori tanah dengan cara mekanis (Hardiyatmo,2017).

Tapi pada pekerjaan pemadatan tanah, timbul suatu masalah yaitu pergerakan lateral tanah akibat dari tanah yang memiliki plastisitas tinggi (IP>30), sehingga dapat menyebabkan heave di daerah sekitar permukaan tanah (Kerbs,1971). Hal ini dapat menyebabkan kerusakan pada bangunan di sekitarnya akibat pergerakan lateral tanah. Pada pemancangan tiang pancang pun dapat terjadi masalah, yaitu terangkatnya tiang pancang (pile heaving) akibat 
efek tumbukan dari tiang pancang di sebelahnya. Hal tersebut dapat terjadi karena adanya kenaikan pada tekanan air pori.

Berdasarkan latar belakang, tujuan dari penelitian ini adalah mendapatkan hasil tambahan tegangan tanah dengan metode Boussinesq, yang nilainya akan berbanding lurus dengan peningkatan tekanan air pori. Serta membandingkan energi dynamic compaction dan tandem roller dengan kegagalan geser metode Terzaghi. Sehingga dapat mengetahui resiko heave yang dapat terjadi di sekitar tanah yang mengalami tekanan gaya vertikal.

Batasan masalah pada penelitian ini adalah perhitungan mengacu pada SNI 8460:2017, tidak memperhitungkan adanya beban gempa, dan tidak memperhitungkan penurunan tanah

\section{Tandem Roller}

Drum roller adalah alat berat yang digunakan untuk memadatkan jalan atau area konstruksi sehingga memiliki tingkat kepadatan yang diinginkan. Jenis roda compactor terbuat dari besi seluruhnya atau ditambah berat berupa pasir atau air, bisa terbuat dari karet (berupa roda ban) dengan bentuk kaki kambing (sheep foot), yang berukuran kecil bisa menggunakan tangan dengan mengarahkan ke bagian yang akan dipadatkan (Rostiyanti, 2004).

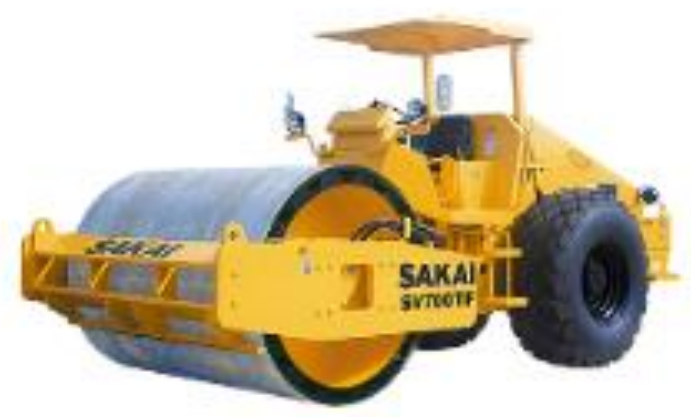

Gambar 1. Drum roller SV700TF (Sumber: www.sakainet.co.jp)

Drum roller SV700TF ini memiliki load on front sebesar $11400 \mathrm{~kg}$ dan memiliki lebar sebesar 2.29 meter. Fungsi dari alat ini adalah:

1) Memadatkan tanah

2) Memadatkan lapis perkerasan (lentur)

3) Memadatkan Lapis Atas (Surface)

\section{Dynamic compaction}

Secara garis besar, pengertian dynamic compaction adalah suatu metode peningkatan kondisi tanah dengan meningkatkan kepadatan tanah dan mengurangi rongga udara di dalam tanah. Target dynamic compaction dicapai dengan menjatuhkan beban (pounder) dari suatu ketinggian tertentu ke atas permukaan tanah yang akan dipadatkan. Proses pemadatan ini berlangsung pada sekian banyak jatuhan pada lahan yang dituju. Dynamic Compaction (DC) adalah salah satu metode perbaikan tanah yang memiliki keunggulan waktu perbaikan tanah yang relatif lebih cepat dan murah dibandingkan dengan metode lain (FHWA, 1995).

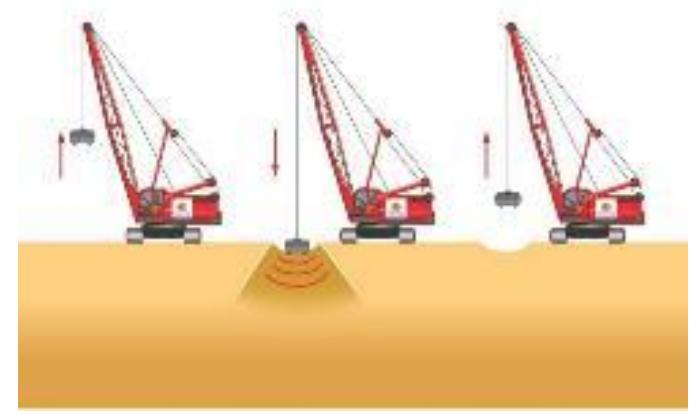

Gambar 2. Cara kerja metode dynamic compaction (Sumber: Alamsyah, 2004) 


\section{Mencari nilai compaction effort (CE)}

Suatu pemadatan tanah adalah usaha (energi) yang dilakukan pada massa tanah. Suatu pemadatan (Compactive Effort=CE) yang dilakukan tersebut adalah fungsi dari variabel-variabel berikut: (Alamsyah, 2004)

$$
\mathrm{CE}=\frac{W \times H \times L \times B}{V}
$$

dengan $\mathrm{CE}=$ Compactive Effort (ton $\left./ \mathrm{m}^{2}\right), \mathrm{W}=$ berat hammer (ton), $\mathrm{H}=$ tinggi jatuh $(\mathrm{m}), \mathrm{L}=$ jumlah layer, $\mathrm{B}=$ jumlah pukulan per layer dan $\mathrm{V}=$ volume tanah $\left(\mathrm{m}^{3}\right)$.

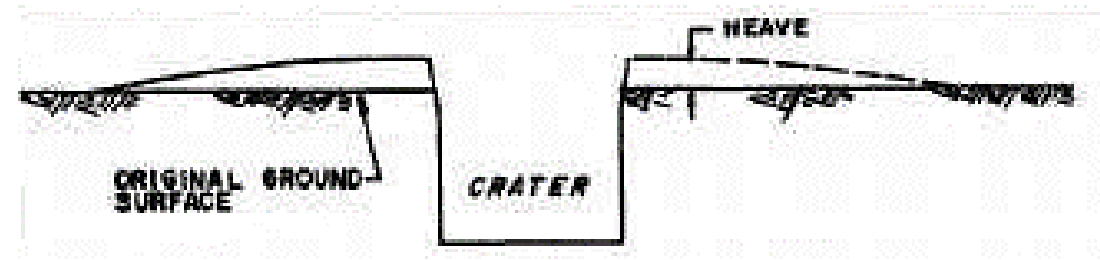

Gambar 3. Sketsa heave pada lubang akibat tumbukan (Sumber: Alamsyah, 2004)

\section{Tiang pancang}

Fondasi tiang pancang (pile foundation) adalah bagian dari struktur yang digunakan untuk menerima dan menyalurkan beban dari struktur atas ke tanah penunjang yang terletak pada kedalaman tertentu (Das, 2000). Tiang pancang bentuknya panjang dan langsing yang menyalurkan beban ke tanah yang lebih dalam. Bahan utama dari tiang adalah kayu, baja (steel), dan beton. Tiang pancang yang terbuat dari bahan ini akan dipukul, di bor atau di dongkrak ke dalam tanah dan dihubungkan dengan pile cap. Tergantung juga pada tipe tanah, material dan karakteistik penyebaran beban tiang pancang diklasifikasikan berbeda-beda

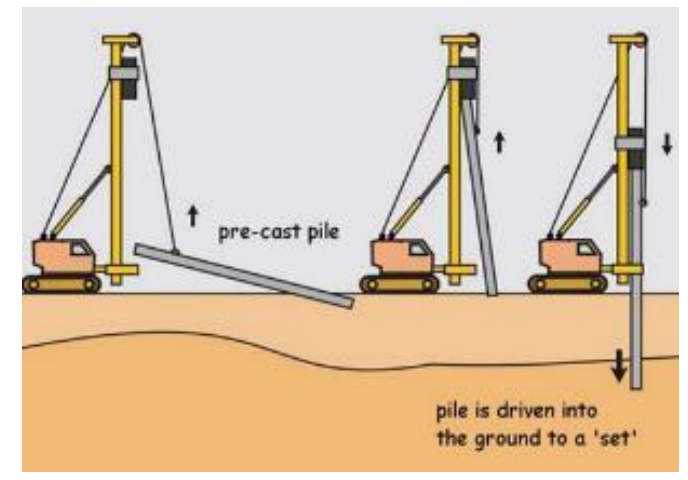

Gambar 4. Proses pemancangan tiang pancang (Sumber: www.solusibetonreadymix.com)

\section{Pergerakan tanah lateral}

Metode pemancangan Jacked-In Pile seringkali menimbulkan masalah terhadap lingkungan sekitar. Pada umumnya, masalah yang terjadi adalah kerusakan bangunan disekitar lokasi pemancangan, dikarenakan proses pemancangan merupakan proses yang menghasilkan desakkan tanah ke arah lateral dengan jumlah tertentu (Hagerty dan Peck, 1971). Desakkan tersebut menyebabkan kenaikan tekanan air pori dalam tanah (Poulos, 1980) dan pergerakan tanah ke arah lateral (Broms, 1981). Besarnya volume tiang pancang yang dimasukkan ke dalam tanah berbanding lurus dengan besar pergerakan tanah yang terjadi (Dugan and Freed, 1984), luas daerah lingkungan sekitar yang terpengaruh, dan besar peningkatan tekanan air pori dalam tanah yang terjadi.

Olsson dan Holm (1993) dengan Metode Hellman/Rehnman menggunakan suatu permodelan dan perumusan tertentu. Disebutkan bahwa pada permukaan tanah, daerah yang dipengaruhi pemancangan suatu grup tiang dengan batas luasan berupa tiang pancang terluar dibatasi hingga jarak sama dengan kedalaman satu buah tiang model. 


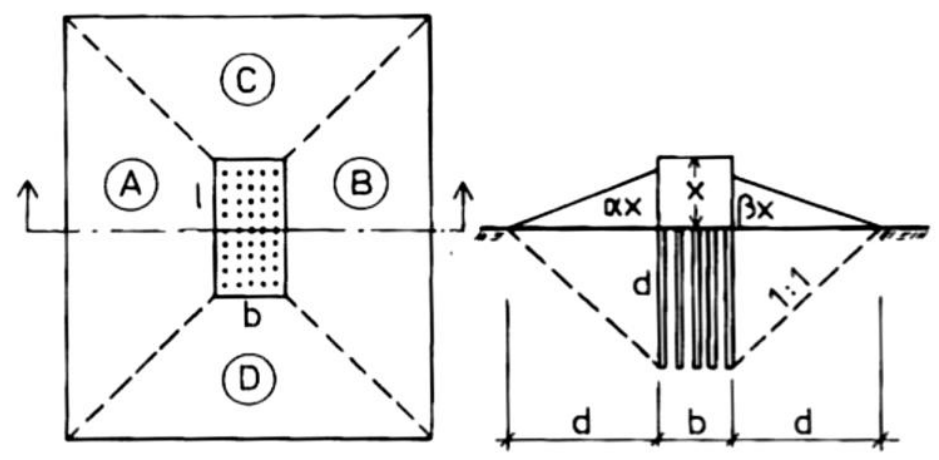

Gambar 5. Pergerakan tanah arah vertikal akibat pemancangan (Sumber: Olsson \& Holm 1993)

Besarnya heave yang terjadi akibat pemancangan dapat diprediksi menggunakan:

$$
\mathrm{x}=\frac{\eta(\text { Vpiles }- \text { Vpreauger })}{\mathrm{d}(\alpha+\beta)\left(\frac{1}{2}+\frac{\mathrm{d}}{3}\right)+(\gamma+\delta)\left(\frac{b}{2}+\frac{d}{3}\right)+\frac{b . l}{d}}
$$

dengan $\mathrm{x}=$ heave $(\mathrm{m})$, Vpiles $=$ volume tiang $\left(\mathrm{m}^{3}\right)$, Vpreauger $=$ volume preaugering $\left(\mathrm{m}^{3}\right), \mathrm{b}=$ lebar bidang grup tiang $(\mathrm{m}), 1=$ panjang bidang grup tiang $(\mathrm{m}), \mathrm{d}=$ kedalaman tiang $(\mathrm{m}), \eta=$ faktor heave, $\alpha=$ faktor heave bangunan $\mathrm{A}, \beta=$ faktor heave bangunan $\mathrm{B}, \gamma=$ faktor heave bangunan $\mathrm{C}$ dan $\delta=$ faktor heave bangunan $\mathrm{D}$.

Faktor heave, $\eta$, mendeskripsikan kompresibilitas tanah lempung yang bernilai antara 0.5 dan 1 . Nilai faktor heave berbanding terbalik dengan tingkat kompresibilitas tanah lempung. Faktor heave, $\alpha-\delta$, merupakan faktor untuk mempertimbangkan beban bangunan disekitar. Nilai faktor heave bervariasi antara 0 dan 1 , di mana 0 berarti bangunan berat dan 1 adalah bangunan ringan. (Olsson \& Holm, 1993)

\section{Distribusi tegangan dalam tanah}

Berdasarkan pengamatan, tegangan vertikal tidak tergantung pada $\mathrm{E}$ dan $\mu$, sedangkan tekanan lateral bergantung pada $\mu$ dan tidak bergantung pada E. Sebelum beban struktur bekerja tanah sudah mengalami tegangan akibat tekanan overburden $(\sigma)$, sedangkan tegangan yang diakibatkan oleh beban struktur dinyatakan dengan tambahan tegangan (stress increment) yaitu $\Delta \sigma$.

Tambahan tegangan vertikal $\left(\Delta \sigma_{\mathrm{z}}\right)$ akibat beban titik dianalisis dengan meninjau sistem tegangan pada koordinat silinder. Tambahan tegangan vertikal $\left(\Delta \sigma_{z}\right)$ pada titik A dalam tanah akibat bebab titik Q di permukaan dinyatakan:

$$
\Delta \sigma \mathrm{z}=\frac{3 Q}{2 \pi \mathrm{z}^{2}} x\left(\frac{1}{1+\left(\frac{r}{z}\right)^{2}}\right)^{\frac{5}{2}}
$$

Faktor pengaruh

$$
I_{b}=\frac{3}{2 \pi} x\left(\frac{1}{1+\left(\frac{r}{z}\right)^{2}}\right)^{\frac{5}{2}}
$$

Sehingga tambahan tegangan vertikal dalam tanah menjadi:

$$
\Delta \sigma_{z}=\frac{Q}{z^{2}} I_{b}
$$

dengan $\Delta \sigma_{z}=$ tambahan tegangan $\left(\mathrm{kN} / \mathrm{m}^{2}\right), Q=$ gaya vertikal $(\mathrm{kN}), z=$ kedalaman $(\mathrm{m}), I_{b}=$ faktor Boussinesq dan $\mathrm{r}$ $=$ jarak horizontal $(\mathrm{m})$. 


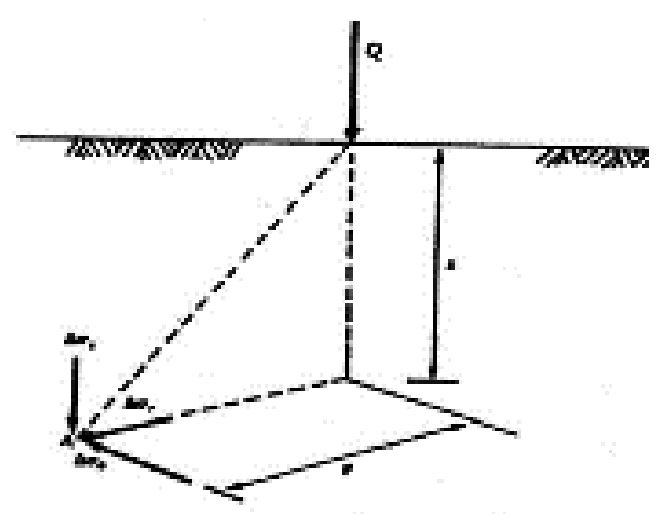

Gambar 6. Tambahan tegangan dan distribusi tegangan dalam tanah akibat baban titik (Sumber: Hardiyatmo, 2017)

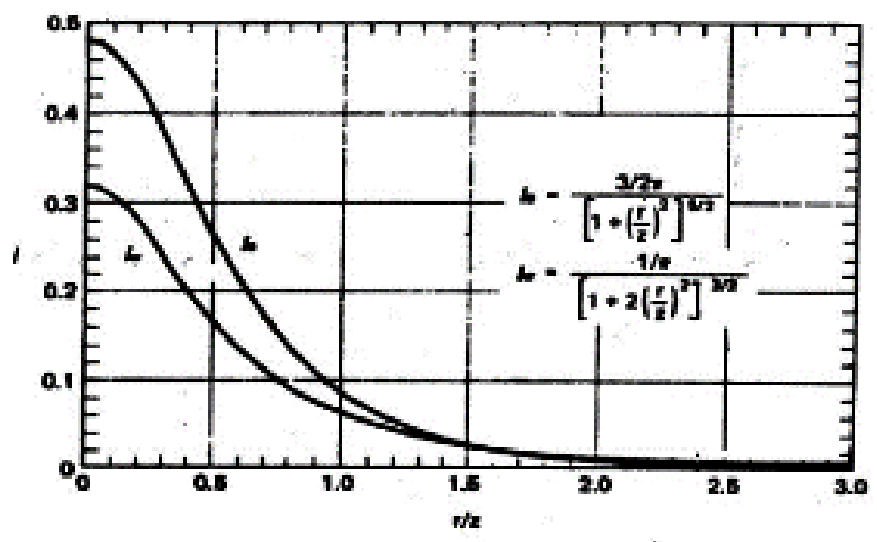

Gambar 7. Nilai faktor pengaruh teori Boussineq dan Westergaard (Sumber: Hardiyatmo, 2017)

\section{Analisis daya dukung Terzaghi}

Karl von Terzaghi adalah seorang insinyur sipil Austria dan geolog, beliau juga disebut bapak mekanika tanah. Beliau memulai mekanika tanah modern dengan teori-teorinya konsolidasi, tekanan lateral tanah, daya dukung, dan stabilitas (Terzaghi, 1943). Terzaghi menganalisi daya dukung tanah dengan anggapan bentuk bujur sangkar dan lingkaran, persamaan daya dukung batas yang disarankan oleh Terzaghi adalah sebagai berikut:

1. Bentuk bujur sangkar:

$$
\mathrm{qult}_{\mathrm{ul}}=1,3 \mathrm{c} \mathrm{Nc}+D f \gamma \mathrm{Nq}+0,4 \gamma \mathrm{B} \mathrm{N \gamma}
$$

2. Bentuk lingkaran:

$$
\mathrm{qult}_{\mathrm{ult}}=1,3 \mathrm{c} \mathrm{Nc}+D f \gamma \mathrm{Nq}+0,3 \gamma \mathrm{R} \mathrm{N} \gamma
$$

3. Bentuk persegi panjang:

$$
\mathrm{q}_{\text {ult }}=\mathrm{c} \mathrm{Nc}(1+0.3 \mathrm{~B} / \mathrm{L})+D f \gamma \mathrm{Nq}+0,5 \gamma \mathrm{B} \mathrm{N} \gamma(1-0.2 \mathrm{~B} / \mathrm{L})
$$

dengan $\mathrm{q}_{\mathrm{ult}}=$ daya dukung ultimate $\left(\mathrm{kN} / \mathrm{m}^{2}\right), \gamma=$ berat volume tanah $\left(\mathrm{kN} / \mathrm{m}^{3}\right), D f=$ kedalaman $(\mathrm{m})$, $\mathrm{c}=\mathrm{kohesi}$ tanah , B = lebar (m), $\mathrm{R}=$ jari-jari (m) dan $\mathrm{Nc}, \mathrm{Nq}, \mathrm{N} \gamma=$ faktor daya dukung Terzaghi.

Rumus daya dukung tanah Terzaghi di atas berlaku pada kondisi "general shear failure" yang terjadi pada tanah padat atau agak keras, yaitu karena desakan Fondasi bangunan pada tanah, maka mula-mula terjadi penurunan kecil, tetapi bila desakan bertambah sampai melampaui batas daya dukung tanah ultimit, maka akan terjadi penurunan yang besar dan cepat, dan tanah di bawah Fondasi akan mendesak tanah sekitarnya ke samping dan menyebabkan tanah tersebut terdesak naik ke atas permukaan tanah. 

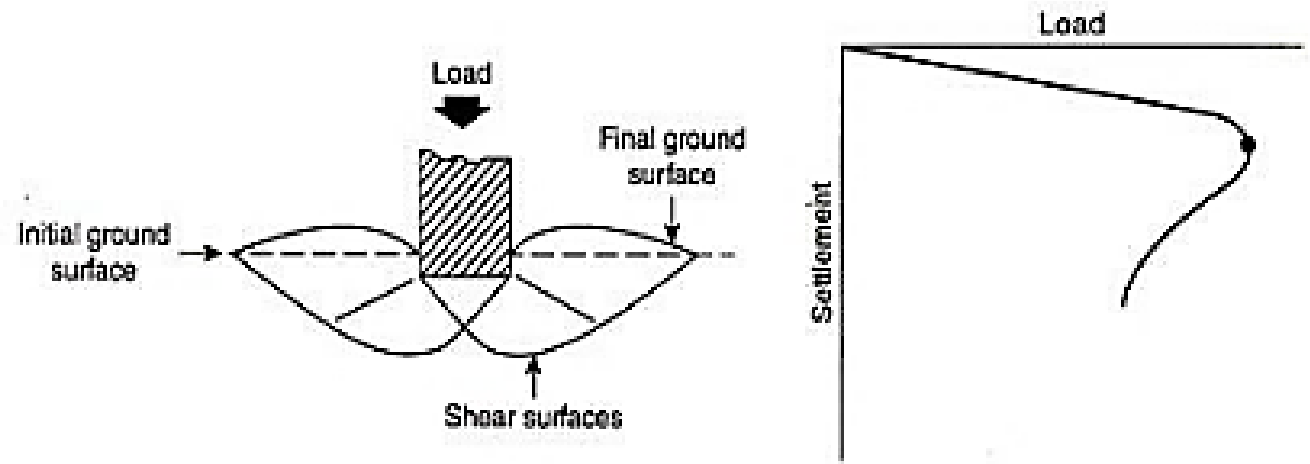

Gambar 8. General shear failure (Sumber: Das, 2000)

\section{Pengaruh peningkatan tekanan air pori akibat pemancangan}

Fondasi merupakan satu elemen yang penting dalam struktur bangunan agar suatu bangunan dapat berdiri dengan kokoh. Walaupun telah banyak perhatian yang diberikan terhadap masalah konstruksi Fondasi tiang selama ini, tetapi pengaruh tentang peningkatan air pori berlebih akibat pemancangan masih belum banyak mendapat perhatian dari pelaku jasa konstruksi.

Fenomena peningkatan tekanan air pori akibat pemancangan tiang telah disadari sejak lama. Poulos dan Davis (1980) telah menyampaikan ringkasan pengukuran peningkatan tekanan air pori pada jenis tanah lempung sensitif dan lempung yang kadar sensitifnya rendah hingga sedang.

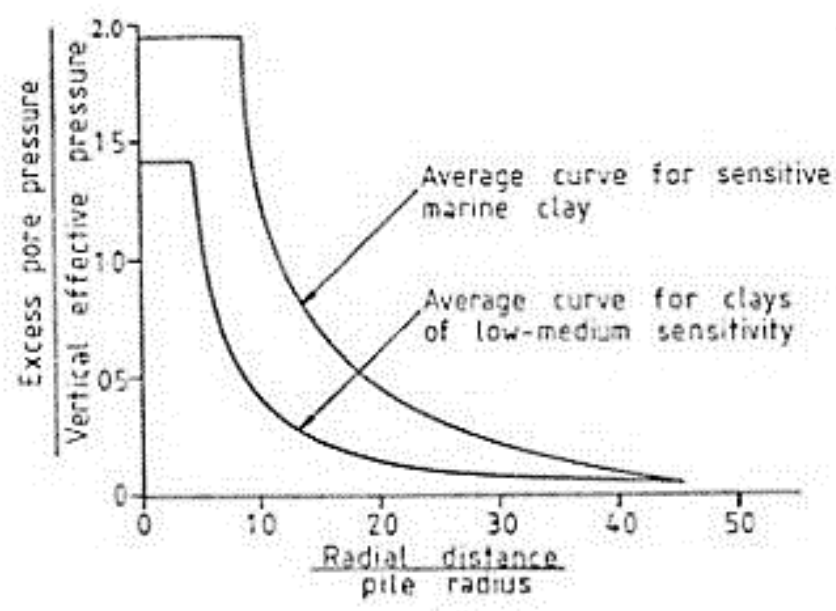

Gambar 9. Pengaruh peningkatan tekanan air pori akibat pemancangan (Sumber: Poulos dan Davis, 1980)

Grafik tersebut menunjukkan bahwa untuk jenis lempung dengan sensitivitas rendah hingga sedang, pada jarak radial di bawah 4 jari-jari tiang peningkatan tekanan air porinya adalah konstan. Sedangkan pada lempung sensitif peningkatan tekanan air pori konstan di bawah 8 jari-jari tiang. Namun, setelah jarak radial dari 4 jari-jari tiang atau sekitar 8 jari-jari tiang terjadi penurunan peningkatan tekanan air pori yang besar.

\section{METODOLOGI PENELITIAN}

\section{Pengumpulan data}

Pada analisis ini, data tanah yang akan dianalisis berlokasi pada daerah Jakarta Utara. Data tanah yang dikumpulkan berupa boring $\log$ dan hasil tes laboratorium. Data tanah tersebut berupa data N-SPT yang kemudian dilakukan korelasi untuk mendapatkan data-data tanah lainnya. 


\section{Diagram alir}

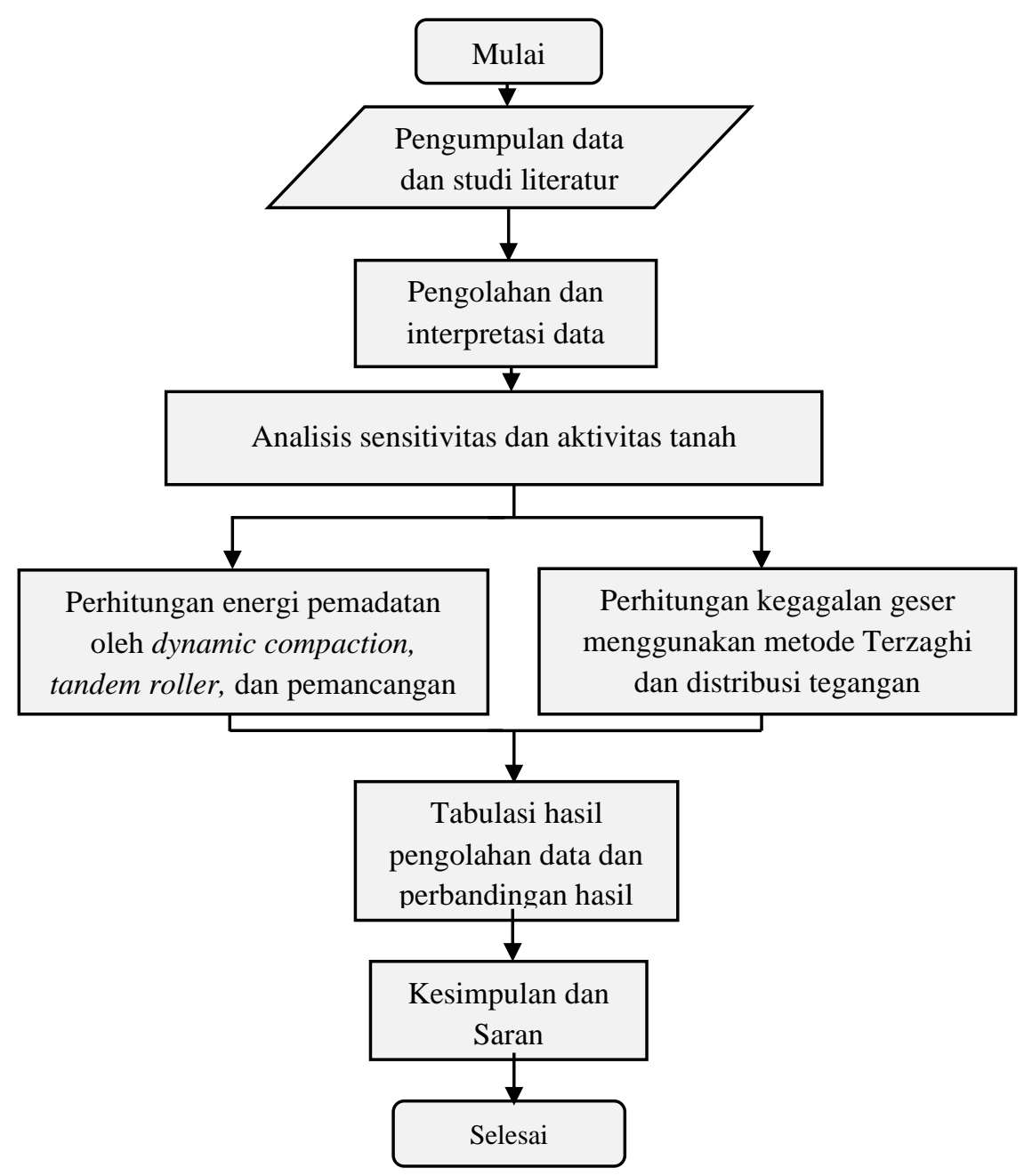

Gambar 10. Diagram Alir

\section{Pengolahan data}

Sebelum dilakukan pengolahan data, perlu dilakukan studi literatur terlebih dahulu. Studi literatur dilakukan untuk memahami dasar-dasar teori yang perlu diperhatikan dan rumus-rumus yang akan dipakai untuk analisis. Setelah dilakukannya studi literatur kemudian dilanjutkan dengan pengolahan data-data tanah yang telah dikumpulkan. Data-data tanah tersebut akan dianalisis secara manual seperti untuk mengkategorikan sensitivitas dan aktivitas tanah. Hasil analisis kegagalan geser dilakukan secara perhitungan manual. Analisis perhitungan kegagalan geser dilakukan dengan perhitungan menggunakan metode yang dirumuskan oleh Terzaghi. Perhitungan juga menggunakan program Microsoft Excel untuk mempermudah perhitungan.

\section{Metode analisis data}

Analisis akan dilakukan dalam 2 kondisi, berdasarkan distribusi tegangan dalam tanah (metode Boussinesq) dan analisis kegagalan geser pada tanah (metode Terzaghi). Kemudian akan mengetahui besarnya kenaikan tekanan air pori berdasarkan distribusi tegangan tanah dan membandingkan hasil nilai kegagalan geser dengan qult akibat tekanan vertikal ke tanah.

\section{ANALISIS DATA DAN HASIL}

Pada Sub-bab berikut akan dilakukan analisis data baik dari segi pengolahan data laboratorium maupun analisis kapasitas dukung metode Terzaghi dan distribusi tengangan Boussinesq. Pada perhitungan metode Boussinesq ini kita dapat mengetahui $\mathrm{q}_{\mathrm{u}}$ tumbukan tiang pancang ke tanah, sehingga nantinya dapat mengetahui besarnya tegangan dalam tanah yang terjadi. Serta pada perhitungan metode Terzaghi kita dapat mengetahui $\mathrm{q}_{\mathrm{u}}$ kegagalan geser yang terjadi. Kemudian hasil tersebut akan kita analisis dengan qu yang terjadi pada tanah dengan menggunakan dynamic 
compaction, tandem roller, dan tiang pancang. Untuk data tanah, kita mengambil di daerah Jakarta Utara karena terletak dekat daerah pantai, dimana sangat mungkin terjadinya kenaikan air pori.

\section{Perbandingan metode Terzaghi dengan hasil gaya vertikal}

Berikut akan membandingkan qult metode Terzaghi dengan gaya vertikal yang dialami oleh tanah. Jika gaya vertikal lebih besar, menandakan terjadinya kegagalan geser (general shear failure) yang akan menyebabkan terjadinya heave.

- Gaya Vertikal Tandem Roller $2194.75 \mathrm{kN} / \mathrm{m}^{2}$

- Gaya Vertikal Dynamic Compaction $2500 \mathrm{kN} / \mathrm{m}^{2}$

$$
\begin{aligned}
& >\text { qult metode Terzaghi } \\
& >522.56 \mathrm{kN} / \mathrm{m}^{2} \text { (terjadi heave) } \\
& >\text { qult }_{\text {metode Terzaghi }} \\
& >885.6 \mathrm{kN} / \mathrm{m}^{2} \text { (terjadi heave) }
\end{aligned}
$$

\section{Distribusi tegangan dalam tanah}

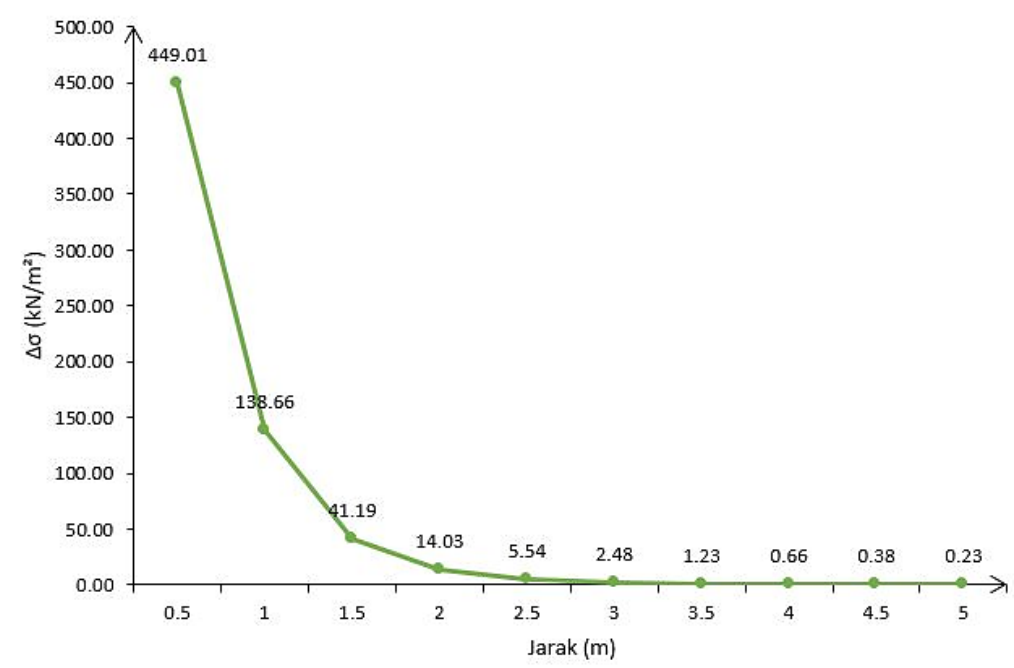

Gambar 11. Grafik Peningkatan Tegangan Tanah pada Kedalaman 1 m

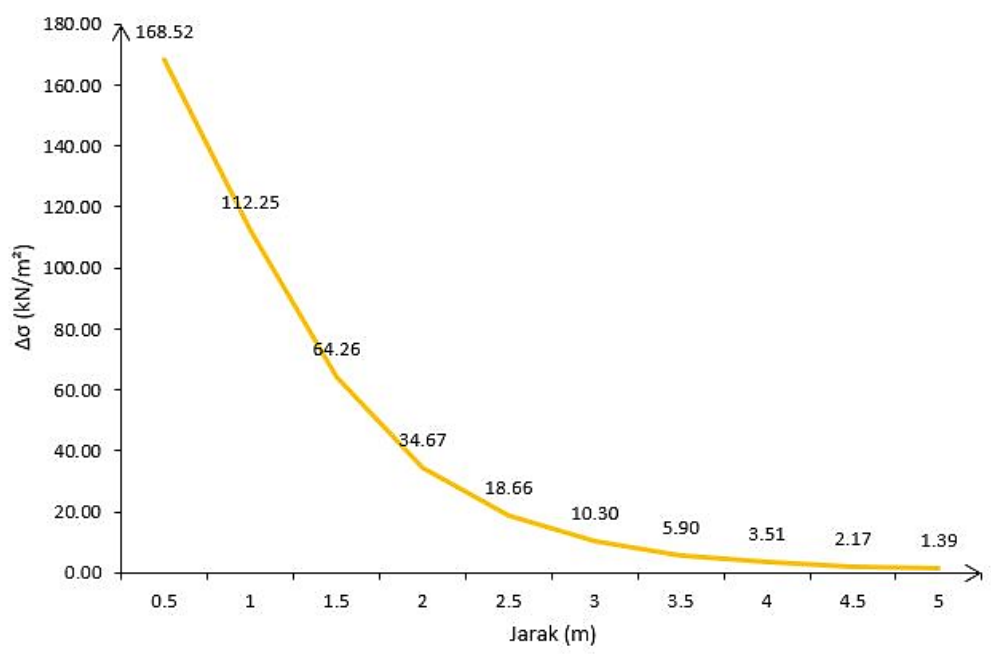

Gambar 12. Grafik Peningkatan Tegangan Tanah pada Kedalaman 2 m 


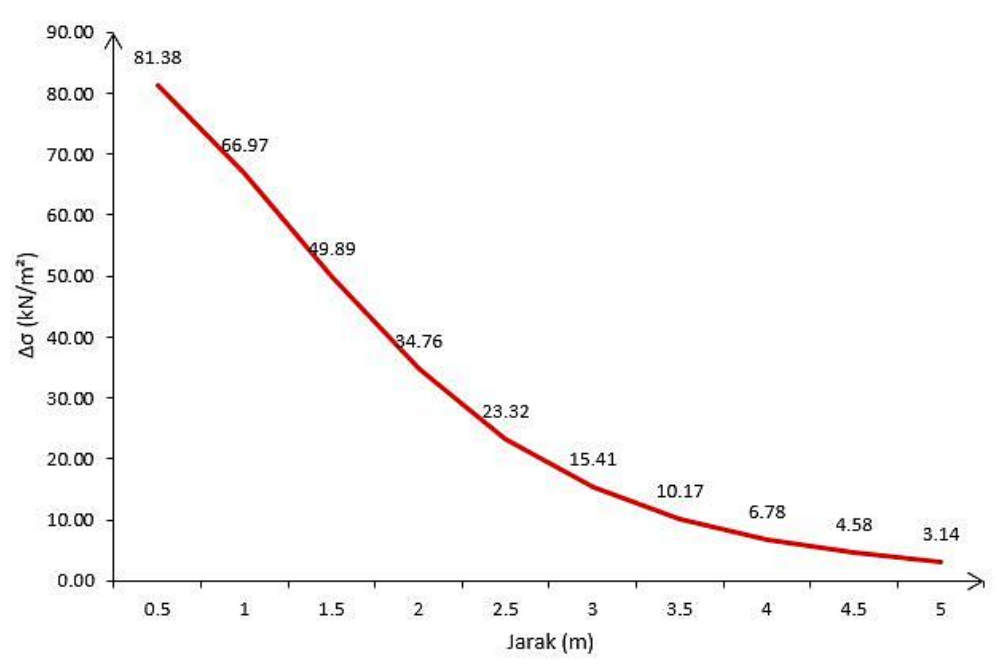

Gambar 13. Grafik Peningkatan Tegangan Tanah pada Kedalaman 3 m

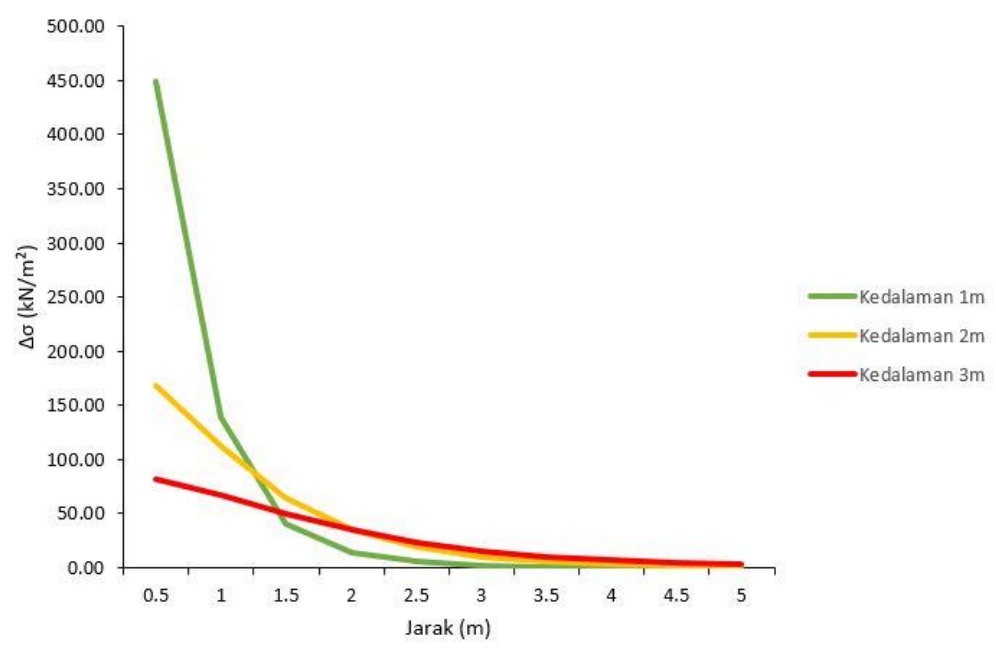

Gambar 14. Grafik Gabungan Perbandingan Peningkatan Tegangan Tanah

\section{Perhitungan metode Olsson \& Holm tanpa preauger}

Pada perhitungan ini, ukuran tiang pancang yang diambil yaitu 0.45 x $0.45 \mathrm{~m}$. Dengan kedalaman sebesar $22 \mathrm{~m}$. Dengan pemakaian preauger didapatkan penurunan heave sebesar $78 \%$ dibandingkan tanpa preauger. Hal ini menandakan pemberian preauger cukup efisien untuk memperkecil heave yang terjadi di sekitar tanah.

Tabel 1. Heave yang terjadi menggunakan metode Olsson

\begin{tabular}{|c|c|c|}
\hline & Tanpa Preauger & Dengan Preauger \\
\hline beban berat (faktor heave 0) & $2200 \mathrm{~cm}$ & $473 \mathrm{~cm}$ \\
\hline beban sedang (faktor heave 0.5 ) & $1.34 \mathrm{~cm}$ & $0.28 \mathrm{~cm}$ \\
\hline beban ringan (faktor heave 1) & $0.67 \mathrm{~cm}$ & $0.14 \mathrm{~cm}$ \\
\hline
\end{tabular}

\section{KESIMPULAN DAN SARAN}

\section{Kesimpulan}

1. Pada perhitungan distribusi tegangan tanah menggunakan metode Boussinesq, didapatkan kesimpulan bahwa semakin dalam dan jauh jarak suatu titik ke energi pemancangan, maka semakin kecil tegangan tanah yang terjadi. Hal tersebut menandakan tekanan air pori berlebih (excess pore water) yang terjadi juga semakin kecil. Pada 
kedalaman $1 \mathrm{~m}$ dengan jarak $0.5 \mathrm{~m}$ menghasilkan tegangan tanah sebesar $449 \mathrm{kN} / \mathrm{m}^{2}$. Sedangkan pada kedalam $1 \mathrm{~m}$ dengan jarak $5 \mathrm{~m}$ menghasilkan tegangan tanah sebesar $0.23 \mathrm{kN} / \mathrm{m}^{2}$.

2. Berdasarkan hasil pengolahan data, besarnya qult kegagalan geser metode Terzaghi lebih kecil daripada qult gaya vertikal dynamic compaction dan tandem roller. Maka akan terjadi heave akibat kegagalan geser yang terjadi pada tanah, sehingga mendesak tanah terdorong ke atas.

- Gaya Vertikal Tandem Roller $>$ qult metode Terzaghi

$2194.75 \mathrm{kn} / \mathrm{m}^{2}>522.56 \mathrm{kN} / \mathrm{m}^{2}$ (terjadi heave)

- $\quad$ Gaya Vertikal Dynamic Compaction > qult metode Terzaghi

$2500 \mathrm{kn} / \mathrm{m}^{2}>885.6 \mathrm{kN} / \mathrm{m}^{2}$ (terjadi heave)

3. Pada perhitungan pergerakan tanah arah vertikal dengan metode Olsson \& Holm, didapatkan semakin besar faktor beban, maka akan semakin besar heave yang terjadi. Pada beban berat (faktor heave 0) terjadi heave sebesar $22 \mathrm{~m}$. Lalu, pada beban sedang (faktor heave 0.5) terjadi heave sebesar $1.34 \mathrm{~cm}$. Kemudian, pada beban ringan (faktor heave 1) terjadi heave sebesar $0.67 \mathrm{~cm}$. Untuk meminimalkan terjadinya heave, maka dilakukan penggunaan preauger lingkaran dengan diameter $0.45 \mathrm{~m}$. Didapatkan hasil yaitu pada beban berat (faktor heave 0 ) terjadi heave sebesar $4.73 \mathrm{~m}$. Lalu, pada beban sedang (faktor heave 0.5) terjadi heave sebesar $0.28 \mathrm{~cm}$. Kemudian, pada beban ringan (faktor heave 1) terjadi heave sebesar $0.14 \mathrm{~cm}$. Terjadi penurunan heave sebesar $78 \%$ dengan menggunakan preauger sebesar diameter tiang pancang.

4. Untuk jenis lempung dengan sensitivitas rendah hingga sedang, pada jarak radial di bawah 4 jari-jari tiang peningkatan tekanan air porinya adalah konstan. Sedangkan pada lempung sensitif peningkatan tekanan air pori konstan di bawah 8 jari-jari tiang. Namun, setelah jarak radial dari 4 jari-jari tiang atau sekitar 8 jari-jari tiang terjadi penurunan peningkatan tekanan air pori yang besar.

\section{Saran}

Untuk meminimalkan terjadinya pergerakan tanah vertical (heave), maka disarankan penggunaan metode dewatering dan prefabricated vertical drain (PVD) untuk menurunkan muka air tanah dan mempercepat proses keluarnya air pori sehingga dapat menghindari tekanan air pori berlebih (excess pore water). Kemudian dapat dilakukan pemancangan dengan metode Hydraulic Static Pile Driver (HSPD) dan penggunaan preauger untuk meminimalisir efek tekanan vertikal yang terjadi pada tanah.

Dari hasil perhitungan dan analisa yang telah dilakukan, didapatkan heave sangat mungkin terjadi akibat gaya vertikal pada tanah. Sehingga dengan adanya makalah ini, penulis berharap agar para pembaca dapat mengantisipasi heave yang akan terjadi akibat adanya gaya vertikal pada tanah. Sebab, heave dapat menyebabkan kerusakan yang fatal pada bangunan atau daerah di atasnya.

\section{DAFTAR PUSTAKA}

Alamsyah, Firman. Perbaikan Daya Dukung Tanah dengan Metoda Dynamic Compaction. Institut Teknologi Sepuluh Nopember, 2014.

Badan Standardisasi Nasional. SNI 8460. 2017: Persyaratan Perancangan Geoteknik. Badan Standardisasi Nasional, 2017.

Broms, Bengt B. Precast Piling Practice. Thomas Telford, Ltd, 1981..

Das, B. M. Principles of Foundation Engineering. Third Edition, PWS Publishing Company, 2000.

Dugan, J. P. dan D. L. Freed. "Ground Heave Due to Pile Driving". International Conference on Case Histories in Geotechnical Engineering, Paper 28, 1984, pp.117-122.

Federal Highway Administration. Dynamic Compaction Geotechnical Engineering Circular vol.1. Federal Highway Administration, 1995.

Gambar Drum Roller SV700TF (On-Line). 7 September 2019: https://www.sakainet.co.jp.

Gambar Proses pemancangan tiang pancang (On-Line). 7 Desember 2019: https:// www.solusibetonreadymix.com.

Hagerty, D. J., dan Ralph B. Peck. "Heave and Lateral Movements Due to Pile Driving". Journal of the Soil Mechanics and Foundation Division, Vol. 97, No. 11, 1971, pp. 1513-1531.

Hardiyatmo, Hary Christady. Mekanika Tanah I. Gajah Mada University Press, 2017.

Olsson, C. dan G. Holm. Pålgrundläggning. AB Svensk Byggtjänst och Statens Geotekniska institut. Stockholm, 1993.

Poulos, H.G,. dan E. H. Davis. Pile Foundation Analysis and Design. John Wiley and Sons, 1980.

Rostiyanti, Fatena Susy. Alat Berat untuk Proyek Konstruksi. Penerbit Rineka Cipta, 2009.

Terzaghi. K. Theoretical Soil Mechanics. John Wiley \& Sons Inc., 1943. 